\title{
Reclassification of Amycolatopsis mediterranei DSM 46095 as Amycolatopsis rifamycinica
} sp. nov.

\author{
Shashi Bala, ${ }^{1}$ Richie Khanna, ${ }^{1}$ M. Dadhwal, ${ }^{1}$ S. R. Prabagaran, ${ }^{2}$ \\ S. Shivaji, ${ }^{2}$ John Cullum ${ }^{3}$ and Rup Lal ${ }^{1}$ \\ ${ }^{1}$ Department of Zoology, University of Delhi, Delhi 110007, India \\ ${ }^{2}$ Centre for Cellular and Molecular Biology, Hyderabad 500007, India \\ ${ }^{3}$ Department of Genetics, Kaiserslautern University of Technology, 67663 Kaiserslautern, \\ Germany
}

Correspondence

Rup Lal

duzdel@del2.vsnl.net.in
Previous experiments have suggested that the rifamycin-producing strain DSM 46095 might not belong to Amycolatopsis mediterranei. Analysis of its 16S rRNA gene sequence and construction of a phylogenetic tree showed most similarity to Amycolatopsis kentuckyensis NRRL B-24129 ${ }^{\top}$, Amycolatopsis lexingtonensis NRRL B-24129 ${ }^{\top}$ and Amycolatopsis pretoriensis NRRL B-24133 ${ }^{\top}$, but the strain was probably not a member of any of these species. Results from DNA-DNA hybridization experiments and comparison of DNA profiling patterns using pulsed-field gel electrophoresis also supported the assignment of strain DSM 46095 to a novel species. Analyses of phospholipids, fatty acid methyl esters and physiological characteristics also showed that the differences between different isolates of $A$. mediterranei and $A$. mediterranei DSM 46095 were as large as those between Amycolatopsis species. Strain DSM 46095 represents a novel species of the genus Amycolatopsis for which the name Amycolatopsis rifamycinica sp. nov. is proposed, with the type strain NT $19^{\top}\left(=\mathrm{DSM} 46095^{\top}=\mathrm{ATCC}^{2} 7643^{\top}\right)$.
Amycolatopsis mediterranei has been the focus of much research because it produces an important antibiotic, rifamycin, whose derivative rifampicin is used extensively against Mycobacterium tuberculosis and Mycobacterium leprae, the causative agents of tuberculosis and leprosy, respectively. A. mediterranei was originally classified as 'Streptomyces mediterranei', later as Nocardia mediterranei and, finally, was transferred to the novel genus Amycolatopsis by Lechevalier et al. (1986). Amycolatopsis belongs to the actinomycete family Pseudonocardiaceae and was first established by Lechevalier et al. (1986) to accommodate four species. The DNA sequences of the rifamycin-biosynthetic gene clusters of strains A. mediterranei S669 (August et al., 1998) and A. mediterranei LBGA3136 (Schupp et al., 1998) have been determined and are essentially identical. The rifamycin-biosynthetic genes of strain A. mediterranei DSM 46095 were cloned, but the restriction pattern was very different from those of the sequenced clusters of strains S669 and LBGA3136 (Kaur et al., 2001). Limited DNA sequencing showed about $10 \%$

Published online ahead of print on 9 January 2004 as DOI 10.1099/ ijs.0.02901-0.

The GenBank accession numbers for the 16S rRNA gene sequences of strains DSM 46095 and F1/24 are respectively AY083603 and AY083604. sequence divergence between the clusters. This degree of sequence divergence suggested that DSM 46095 might represent a different species, but it was also possible that one of the clusters had been introduced into the strain by horizontal transfer. Because of the commercial importance of rifamycin, details of strain derivation are not always clear. It was therefore decided to examine five further strains (Table 1) and to compare them with A. mediterranei DSM $43304^{\mathrm{T}}$ and DSM 46095.

\section{5 rDNA sequence analysis}

Genomic DNA was isolated from A. mediterranei DSM 46095 and from A. mediterranei $\mathrm{F} 1 / 24$, the latter an industrially improved derivative of $A$. mediterranei ATCC $13685^{\mathrm{T}}$, using the method described by Kaur et al. (2001). PCR amplification of the 16S rRNA genes and sequencing were carried out as described by Reddy et al. (2000). The sequences for DSM 46095 and F1/24 show nine mismatches and nine nucleotides in insertions/deletions in 1461/1465 nucleotides, respectively, which supports the suggestion that the strains belong to different species. Similarity searches using BLAST showed closest similarity of the two sequences to A. mediterranei NRRL B-3240 ${ }^{\mathrm{T}}$ and six further accepted Amycolatopsis species whose $16 \mathrm{~S}$ rDNA sequences were included in the analysis. The sequences were aligned using 
Table 1. Strains used for the present study

\begin{tabular}{|c|c|c|}
\hline Strain & Characteristic & Reference/source \\
\hline \multicolumn{3}{|l|}{ A. mediterranei: } \\
\hline DSM $43304^{\mathrm{T}}\left(=\right.$ ATCC $13685^{\mathrm{T}}=$ KCTC $\left.1739^{\mathrm{T}}\right)$ & Rifamycin SV & Margalith \& Beretta (1960) \\
\hline $\mathrm{T}-195^{*}$ & Protorifamycin & Ghisalba et al. (1984) \\
\hline $\mathrm{F} 1 / 24^{\star}$ & Protorifamycin & Ghisalba et al. (1984) \\
\hline DSM 40773 & Rifamycin & Lechevalier et al. (1986) \\
\hline MTCC17 ( = ATCC 21271) & Rifamycin SV & Lancini \& Hengeller (1971) \\
\hline DSM 46096 (=ATCC 21411) & Rifamycin derivative & Hengeller et al. (1973) \\
\hline DSM 46095 (=ATCC 27643) & Rifamycin SV & Birner et al. (1972) \\
\hline A. kentuckyensis NRRL B-24129 & Placentitis in horses & D. P. Labeda, NRRL \\
\hline A. lexingtonensis NRRL B-24131 ${ }^{\mathrm{T}}$ & Placentitis in horses & D. P. Labeda, NRRL \\
\hline A. pretoriensis NRRL B- $24133^{\mathrm{T}}$ & Placentitis in horses & D. P. Labeda, NRRL \\
\hline
\end{tabular}

${ }^{\star}$ CIBA GEIGY, presently known as Novartis, Switzerland.

the CLUSTAL W program (Thompson et al., 1994) at the European Bioinformatics Institute web site (http://www. ebi.ac.uk). The alignment was edited to remove terminal nucleotides not present in all nine sequences. All phylogenetic analyses were carried out using the PHYLIP package, version 3.5c (Felsenstein, 1993). The evolutionary distance matrix was calculated using the Kimura two-parameter method (Kimura, 1980) and an evolutionary tree (Fig. 1) was constructed using the neighbour-joining method (Saitou \& Nei, 1987). The tree topology was evaluated by carrying out bootstrap analysis based on 1000 resamplings using the SEQBOOT and CONSENSE programs (Fig. 1). Parsimony analysis was performed for the aligned sequence data using DNAPARS, including a bootstrap analysis with 100 resamplings (data not shown). This produced a tree topology very similar to that constructed using the neighbour-joining method. Fig. 1 shows that DSM 46095 grouped with three recently described species of Amycolatopsis, Amycolatopsis kentuckyensis NRRL B-24129 ${ }^{\mathrm{T}}$, Amycolatopsis lexingtonensis NRRL B-24129 $9^{\mathrm{T}}$ and Amycolatopsis pretoriensis NRRL B-24133 ${ }^{\mathrm{T}}$ (Labeda et al., 2003). However, DSM 46095 seems to be distinct from these three species, with six mismatches and four insertions/deletions in comparison with the closest species, A. kentuckyensis. The $16 \mathrm{~S}$ rRNA gene sequence of strain F1/24 is very similar to that of the type strain, DSM $43304^{\mathrm{T}}$ (two mismatches), and, as $\mathrm{F} 1 / 24$ is derived from this strain, it is likely that the differences reflect sequencing errors.

\section{DNA-DNA hybridization}

DNA was extracted from the three strains of $A$. mediterranei (DSM $43304^{\mathrm{T}}, \mathrm{F} 1 / 24$ and DSM 46095), A. kentuckyensis, A. lexingtonensis and A. pretoriensis following the procedure described by Kaur et al. (2001). DNA-DNA hybridization was carried out using the membrane filter method (Tourova \& Antonov, 1987). The quality of the DNA preparation was checked by spectrophotometry and agarose gel electrophoresis (Sambrook \& Russell, 2000). Ten micrograms of denatured DNA was immobilized on each nitrocellulose membrane filter and DNA was labelled with $\left[\alpha-{ }^{32} \mathrm{P}\right] \mathrm{dATP}$ (BRIT, India) using a nick translation kit (Amersham Pharmacia). Hybridization was performed overnight at $65{ }^{\circ} \mathrm{C}$. After hybridization, the filters were washed with SSC and SDS to remove the unbound probe. The amount of bound probe DNA was estimated using a scintillation counter (Beckman Instruments) and levels of hybridization were expressed as percentages of the probe bound relative to the homologous reaction. In initial experiments performed with triplicate filters, DNA from strains DSM $43304^{\mathrm{T}}$, F1/24 and 46095 was bound to the filter and hybridized with DNA probe from DSM $43304^{\mathrm{T}}$. This gave a level of hybridization of $100 \%$ for DSM $43304^{\mathrm{T}}$ and F1/24, as expected. By contrast, DSM 46095 gave a level of hybridization of only

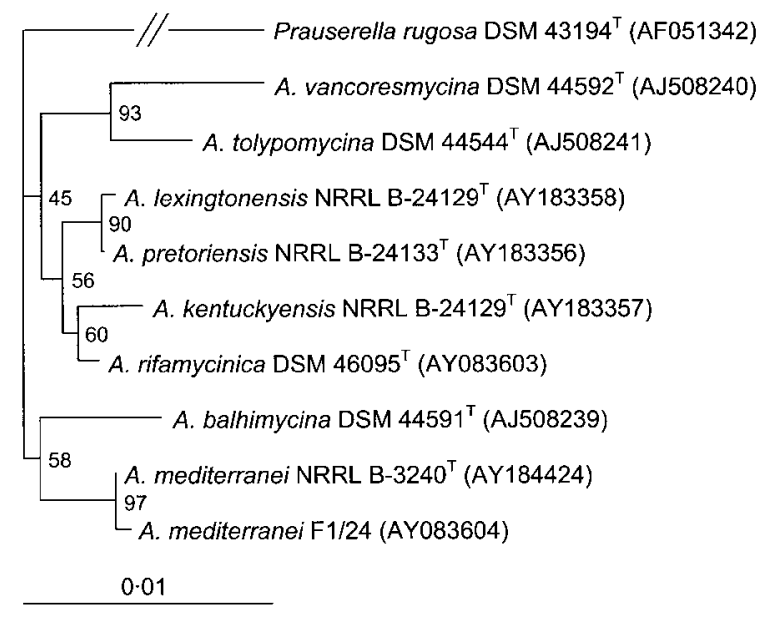

Fig. 1. Phylogenetic tree based on $16 \mathrm{~S}$ rRNA gene sequences showing Amycolatopsis species related to Amycolatopsis rifamycinica sp. nov. The tree was constructed by the neighbourjoining method and rooted by using Prauserella rugosa as an outgroup. Bootstrap values, expressed as percentages based on 1000 replicates, are given at branch points. Bar, 0.01 nucleotide substitutions per site. 
$40 \%$, supporting the suggestion that this strain represents a different species, because two members of the same species should usually show at least $70 \%$ hybridization. These results were confirmed from similar experiments in which DSM 46095 DNA was used as probe. Experiments in which DNA from DSM 46095 was bound to filters and hybridized with DNA from A. kentuckyensis NRRL B-24129 A. lexingtonensis NRRL B-24131 ${ }^{\mathrm{T}}$ and A. pretoriensis NRRL $\mathrm{B}-24133^{\mathrm{T}}$ gave hybridization values of 67,47 and $48 \%$, respectively. The reciprocal hybridization experiment in which DSM 46095 DNA was used as a probe gave similar results.

\section{Pulsed-field gel electrophoresis of strains classified as $A$. mediterranei}

The seven strains that had been classified as A. mediterranei were also examined using pulsed-field gel electrophoresis. Strains F1/24 and T-195 were derived from the type strain $\left(\right.$ DSM $43304^{\mathrm{T}}$ ) in an industrial strain-improvement programme involving successive rounds of mutagenesis (Ghisalba et al., 1984). Strains MTTC 17 and DSM 46096 (Table 1) were also derived by mutagenesis from the type strain. DNA was prepared in agarose blocks using the method of Beyazova et al. (1995). Restriction digests were performed as in Pandza et al. (1997). Electrophoresis was performed in $0.5 \times \mathrm{TBE}$ buffer at $14{ }^{\circ} \mathrm{C}$ using a CHEF DR III system (Bio-Rad). Lambda DNA concatemers (New England Biolabs) and AseI digests of total DNA of Streptomyces coelicolor M145 (Kieser et al., 1992) were used as molecular size standards. Four different restriction enzymes (AseI, DraI, BfrI and XbaI), which cut infrequently in DNA of high G $+C$ content, were tested. AseI gave the most suitable restriction profiles, with 10-20 fragments (Fig. 2). It can be seen that the patterns for five of the strains

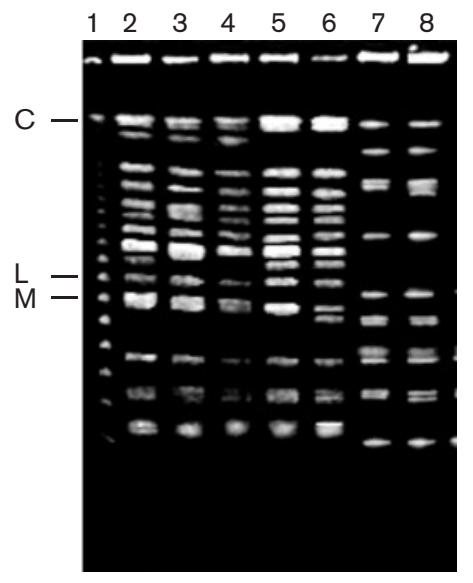

Fig. 2. Restriction profiles of Asel-digested DNA of $A$. mediterranei strains (pulse time: $5-90 \mathrm{~s}$, run time: $36 \mathrm{~h}$, voltage: 200 V). Lanes: 1, lambda ladder PFGE marker; 2, DSM $43304^{\mathrm{T}}$; 3, T-195; 4, F1/24; 5, DSM 40773; 6, MTCC17; 7, DSM 46096; and 8, DSM 46095. (lanes 2-6) are similar, whereas the patterns for strains DSM 46096 and DSM 46095 (lanes 7 and 8) resemble each other, but differ from those of the other five strains. The AseI DNA fragments revealed no significant differences in genome size between the seven strains (between 7.9 and 8.4 Mb; data not shown). These data thus indicate that five of the strains are A. mediterranei, whereas DSM 46096 appears to represent a second member of the novel species represented by strain DSM 46095. This result is unexpected, because DSM 46096 is considered to be a mutant of the type strain A. mediterranei ATCC $13685^{\mathrm{T}}$ (Hengeller et al., 1973). It has clearly different morphological and physiological properties from DSM 46095 (see below).

\section{Phenotypic properties}

The colour, shape, size and contour of colonies of the seven strains producing rifamycin or related compounds were observed on YM medium at $28^{\circ} \mathrm{C}$ for 7 days. The culture conditions were as described by Lal et al. (1998). All strains showed the expected branched mycelial growth, but there was considerable variation between strains in colony morphology and pigmentation. DSM 46095 sporulated poorly and produced two types of colonies (orange with a pitted mucoid-like surface and pale orange with a smooth mucoid-like surface); poor sporulation and the production of two colony types (on glucose/asparagine medium) were reported previously by Birner et al. (1972). DSM 46096 produced yellowish colonies and showed poor to moderate sporulation.

Polar lipids were extracted from DSM 46095 as in Kates (1972) and identified by TLC. The predominant phospholipids were cardiolipin, phosphatidylethanolamine, phosphatidylglycerol and a small amount of phosphatidylinositol. Some other unidentified spots were also seen on the TLC plate. Fatty acid methyl esters were extracted from wet cells of DSM 46095 as described by Sato \& Murata (1988) and were separated on a gas chromatograph (HP5890 series) using a DB-23 capillary column (30 m $\times 0.25 \mathrm{~mm}$; J and W Scientific). The fatty acid methyl ester profile was: $25 \% 18: 1,24 \% 16: 0$ iso, $11 \% 17: 0$ anteiso, $9 \% 17: 0$ iso, $8 \% 16: 0,4 \% 17: 1,4 \% 18: 4,3 \% 15: 0$ iso and other minor components.

The seven strains were subjected to various physiological tests. Growth at different temperatures was analysed and catalase tests were carried out as described by McCarthy \& Cross (1984) using YM medium. Hydrolysis of Tweens 20 and 80 and the ability of the strains to grow in the presence of $\mathrm{NaCl}$ were tested as described by Arden Jones et al. (1979). Acid production from carbohydrates and degradation of xanthine and hypoxanthine were examined as described by Gordon et al. (1974). Urease activity was detected as in Christensen (1946). The other physiological tests and methods were as described by Collins et al. (1989). All seven strains were urease-positive and none produced amylase. In addition, all the strains could utilize dextrin, D-fructose, D-glucose, sucrose, trehalose, Tweens 20 and 80, 
hypoxanthine and aesculin and could not utilize xanthine or allantoin. They grew in the temperature range $10-37^{\circ} \mathrm{C}$ but not at $45^{\circ} \mathrm{C}$. Results were compared with published results for the other strains in the monophyletic clade shown in Fig. 1 (Table 2). The differential properties may not be species specific because five of the strains (DSM $43304^{\mathrm{T}}, \mathrm{F} 1 /$ 24, T-195, MTCC 17 and DSM 40733) and the other two strains (DSM $46095^{\mathrm{T}}$ and DSM 46096) of A. mediterranei showed differences within the species as large as those between species. Although the loss of many properties by F1/24 and T-195 compared to the parent DSM $43304^{\mathrm{T}}$ (Table 2) could be explained by mutagenesis during strain improvement, it seems less likely that the ability of DSM 46096 to utilize lactose, maltose and mannitol has arisen by mutagenesis from a non-utilizing ancestor similar to DSM 46096. However, evaluation of the gross morphological characteristics and differential physiological properties of strain DSM 46095 is generally consistent with the molecular systematic observations and clearly demonstrated that strain DSM 46095 represents a novel species of the genus Amycolatopsis for which the name Amycolatopsis rifamycinica sp. nov. is proposed, with the type strain NT $19^{\mathrm{T}}$.

\section{Description of Amycolatopsis rifamycinica sp. nov.}

Amycolatopsis rifamycinica (N.L. n. rifamycinum -i rifamycin; L. suff. icus-a-um related to; N.L. fem. adj. rifamycinica referring to the ability to produce rifamycin).
Orange-coloured vegetative mycelium is produced in yeast extract agar and glucose/asparagine agar and white to very pale pink aerial mycelium on oatmeal agar and yeast extract/ molasses agar. A light pale to brown yellow pigment is produced on tyrosine agar, yeast extract/glucose agar and oatmeal agar. Aerobic and catalase-positive. Casein, aesculin, gelatin, hypoxanthine and urea are hydrolysed. Starch, allantoin and xanthine are not hydrolysed or decomposed. Acid is produced from adonitol, glucose, fructose, arabinose, dextrin, sucrose, trehalose, xylose and cellobiose. No acid is produced from lactose, maltose, mannitol, rhamnose and raffinose. Grows weakly in the presence of $5 \% \mathrm{NaCl}$ $(w / v)$. Temperature range for growth is $10-37^{\circ} \mathrm{C}$.

The type strain, NT $19^{\mathrm{T}}\left(=\operatorname{DSM} 46095^{\mathrm{T}}=\right.$ ATCC $\left.27643^{\mathrm{T}}\right)$, was isolated from a soil sample in an arid region near Alice Springs, Northern Territory, Australia, by Birner et al. (1972) and produces rifamycin SV.

\section{Acknowledgements}

This work was funded by grants from the Department of Biotechnology. We would like to thank the Department of Science and Technology (Government of India) and the Deutsche Akademische Austauschdienst for a project-based exchange programme grant. We are also grateful to D. P. Labeda for providing three strains (A. kentuckyensis, A. lexingtonensis and A. pretoriensis). S. B. and M.D. gratefully acknowledge CSIR (Government of India) for

Table 2. Differences in the physiological characteristics of Amycolatopsis strains

Strains: 1-5, A. mediterranei strains DSM 43304 ${ }^{\mathrm{T}}$ (1), F1/24 (2), T-195 (3), MTCC 17 (4) and DSM 40773 (5); 6, A. rifamycinica DSM $46095^{\mathrm{T}}$; 7, A. rifamycinica DSM 46096; 8, A. kentuckyensis NRRL B-14129 ${ }^{\mathrm{T}}$ (data from Labeda et al., 2003); 9, A. lexingtonensis NRRL B$24131^{\mathrm{T}}$ (Labeda et al., 2003); 10, A. pretoriensis NRRL B-24133 ${ }^{\mathrm{T}}$ (Labeda et al., 2003); 11, A. tolypomycina DSM $44544^{\mathrm{T}}$ (Wink et al., 2003); 12, A. vancoresmycina DSM 44592 ${ }^{\mathrm{T}}$ (Wink et al., 2003); 13, A. balhimycina DSM 44591 ${ }^{\mathrm{T}}$ (Wink et al., 2003). +, Positive; -, negative; $\mathrm{W}$, weakly positive; ND, not done.

\begin{tabular}{|c|c|c|c|c|c|c|c|c|c|c|c|c|c|}
\hline Characteristic & 1 & 2 & 3 & 4 & 5 & 6 & 7 & 8 & 9 & 10 & 11 & 12 & 13 \\
\hline \multicolumn{14}{|l|}{ Acid production from: } \\
\hline Adonitol & - & - & - & - & - & + & - & + & + & - & $\mathrm{ND}$ & $\mathrm{ND}$ & $\mathrm{ND}$ \\
\hline Cellobiose & + & - & - & - & + & + & + & + & + & + & $\mathrm{ND}$ & $\mathrm{ND}$ & $\mathrm{ND}$ \\
\hline D-Galactose & + & - & - & - & + & + & + & + & + & + & ND & $\mathrm{ND}$ & ND \\
\hline Maltose & + & - & - & + & + & - & + & + & + & + & $\mathrm{ND}$ & $\mathrm{ND}$ & ND \\
\hline D-(-)-Mannitol & + & - & - & - & + & - & + & - & $\mathrm{W}$ & - & + & + & + \\
\hline Raffinose & + & - & - & - & - & - & - & + & + & + & - & + & + \\
\hline L- $(+)$-Rhamnose & + & - & - & + & - & - & - & + & + & + & + & + & + \\
\hline D-(-)-Sorbitol & $\mathrm{W}$ & - & - & - & - & - & - & + & - & $\mathrm{w}$ & $\mathrm{ND}$ & $\mathrm{ND}$ & ND \\
\hline Growth in the presence of $5 \% \mathrm{NaCl}$ & + & - & - & + & + & $\mathrm{W}$ & $\mathrm{W}$ & + & + & + & ND & $\mathrm{ND}$ & ND \\
\hline Production of catalase & + & $\mathrm{W}$ & $\mathrm{W}$ & + & + & + & + & $\mathrm{ND}$ & $\mathrm{ND}$ & $\mathrm{ND}$ & $\mathrm{ND}$ & $\mathrm{ND}$ & ND \\
\hline
\end{tabular}


providing senior research fellowships. We would like to thank $\mathrm{K}$. H. Gartemann for his valuable advice and J. P. Euzéby for etymological advice.

\section{References}

Arden Jones, M. P., McCarthy, A. J. \& Cross, T. (1979). Taxonomic and serological studies on Micropolyspora faeni and Micropolyspora strains from soil bearing the specific epithet rectivirgula. J Gen Microbiol 115, 343-354.

August, P. R., Tang, L., Yoon, Y. J. \& 9 other authors (1998). Biosynthesis of the ansamycin antibiotic rifamycin: deductions from the molecular analysis of the rif biosynthetic gene cluster of Amycolatopsis mediterranei. Chem Biol 5, 69-79.

Beyazova, M. L., Brodsky, B. C., Shearer, M. C. \& Horan, A. C. (1995). Preparation of actinomycete DNA for pulsed-field gel electrophoresis. Int J Syst Bacteriol 45, 852-854.

Birner, J., Hodgson, P. R., Lane, W. R. \& Baxter, E. H. (1972). An Australian isolate of Nocardia mediterranea producing rifamycin SV. J Antibiot 25, 356-359.

Christensen, W. B. (1946). Urea decomposition as a means of differentiating Proteus and para-colon cultures from each other and from Salmonella and Shigella types. J Bacteriol 52, 461-466.

Collins, C. H., Lyne, P. M. \& Grange, J. M. (1989). Microbiological Methods, 6th edn. London: Butterworth.

Felsenstein, J. (1993). PHYLIP (Phylogeny Inference Package), version 3.5c. Distributed by the author. Department of Genetics, University of Washington, Seattle, USA.

Ghisalba, O., Auden, J. A. L., Schuup, T. \& Nuesch, J. (1984). The rifamycins: properties, biosynthesis and fermentation. In Biotechnology of Industrial Antibiotics, pp. 281-327. Edited by E. J. Vandamme. New York: Marcel Dekker.

Gordon, R. E., Barnett, D. A., Handerhan, J. E. \& Pang, C. H.-N. (1974). Nocardia coeliaca, Nocardia autotrophica, and the nocardin strain. Int J Syst Bacteriol 24, 54-63.

Hengeller, C., Lancini, G. \& Sensi, P. (1973). 27-Demethoxy-27hydroxyrifamycin derivatives. US Patent 3,743,635. Washington, DC: US Government Patent Office.

Kates, M. (1972). In Techniques in Lipidology, p. 351. Edited by T. S. Work \& E. Work. New York: Elsevier.

Kaur, H., Cortes, J., Leadlay, P. \& Lal, R. (2001). Cloning and partial characterization of the putative rifamycin biosynthetic gene cluster from the actinomycete Amycolatopsis mediterranei DSM 46095. Microbiol Res 156, 239-246.

Kieser, H. M., Kieser, T. \& Hopwood, D. A. (1992). A combined genetic and physical map of the Streptomyces coelicolor A3 (2) chromosome. J Bacteriol 174, 5496-5507.

Kimura, M. (1980). A simple method for estimating evolutionary rates of base substitutions through comparative studies of nucleotide sequences. J Mol Evol 16, 111-120.

Labeda, D. P., Donahue, J. M., Williams, N. M., Sells, S. F. \& Henton, M. M. (2003). Amycolatopsis kentuckyensis sp. nov., Amycolatopsis lexingtonensis sp. nov. and Amycolatopsis pretoriensis sp. nov., isolated from equine placentas. Int J Syst Evol Microbiol 53, 1601-1605.

Lal, R., Khanna, R., Dhingra, N., Khanna, M. \& Lal, S. (1998). Development of an improved cloning vector and transformation system in Amycolatopsis mediterranei (Nocardia mediterranei). J Antibiot 51, 161-169.

Lancini, P. \& Hengeller, C. (1971). Preparation of the antibiotic rifamycin SV. US Patent 3,597,324. Washington, DC: US Government Patent Office.

Lechevalier, M. P., Prauser, H., Labeda, D. P. \& Ruan, J.-S. (1986). Two new genera of nocardioform actinomycetes: Amycolata gen. nov. and Amycolatopsis gen. nov. Int J Syst Bacteriol 36, 29-37.

Margalith, P. \& Beretta, G. (1960). Rifamycin. IX. Taxonomic study on Streptomyces mediterranei nov. sp. Mycopathol Mycol Appl 13, 321-330.

McCarthy, A. J. \& Cross, T. (1984). A taxonomic study of Thermomonospora and other monosporic actinomycetes. J Gen Microbiol 130, 5-25.

Pandza, K., Pfalzer, G., Cullum, J. \& Hranueli, D. (1997). Physical mapping shows that the unstable oxytetracycline gene cluster of Streptomyces rimosus lies close to one end of the linear chromosome. Microbiology 143, 1493-1501.

Reddy, G. S. N., Aggarwal, R. K., Matsumoto, G. I. \& Shivaji, S. (2000). Arthrobacter flavus sp. nov., a psychrophilic bacterium isolated from a pond in McMurdo Dry Valley, Antarctica. Int J Syst Evol Microbiol 50, 1553-1561.

Saitou, N. \& Nei, M. (1987). The neighbor-joining method: a new method for reconstructing phylogenetic trees. Mol Biol Evol 4, $406-425$.

Sambrook, J. \& Russell, D. W. (2000). Molecular Cloning: a Laboratory Manual, 3rd edn. Cold Spring Harbor, NY: Cold Spring Harbor Laboratory.

Sato, N. S. \& Murata, N. (1988). Membrane lipids. Methods Enzymol 167, 251-259.

Schupp, T., Toupet, C., Engel, N. \& Goff, S. (1998). Cloning and sequence analysis of the putative rifamycin polyketide synthase gene cluster from Amycolatopsis mediterranei. FEMS Microbiol Lett 159, 201-207.

Thompson, J. D., Higgins, D. G. \& Gibson, T. J. (1994). CLUSTAL W: improving the sensitivity of progressive multiple sequence alignment through sequence weighting, position-specific gap penalties and weight matrix choice. Nucleic Acids Res 22, 4673-4680.

Tourova, T. P. \& Antonov, A. S. (1987). Identification of microorganisms by rapid DNA-DNA hybridization. Methods Microbiol 19, 333-355.

Wink, J. M., Kroppenstedt, R. M., Ganguli, B. N., Nadkarni, S. R., Schumann, P., Seibert, G. \& Stackebrandt, E. (2003). Three new antibiotic producing species of the genus Amycolatopsis, Amycolatopsis balhimycina sp. nov., A. tolypomycina sp. nov., A. vancoresmycina sp. nov., and description of Amycolatopsis keratiniphila subsp. keratiniphila subsp. nov. and A. keratiniphila subsp. nogabecina subsp. nov. Syst Appl Microbiol 26, 38-46. 